\title{
Automatic Train Operation Speed Profile Optimization and Tracking with Multi-Objective in Urban Railway
}

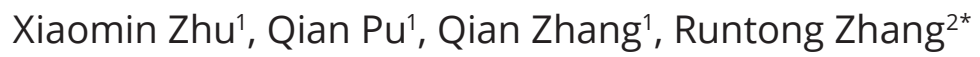 \\ 1 Department of Mechanical Engineering, School of Mechanical, Electronic and Control Engineering, Beijing Jiaotong University, \\ No. 3 Shangyuancun, Haidian District, 100044 Beijing, China \\ 2 Department of Information Management, School of Economics and Management, Beijing Jiaotong University, \\ No. 3 Shangyuancun, Haidian District, 100044 Beijing, China \\ * Corresponding author, e-mail: rtzhang@bjtu.edu.cn
}

Received: 05 February 2018, Accepted: 16 July 2018, Published online: 14 June 2019

\begin{abstract}
Besides energy-efficiency, people also want train operation to be comfortable, punctual and parking precise. In this paper, a multiobjective model for automatic train operation in urban railway is proposed by unifying dimensions of different objectives firstly. This model is built by applying multi-objective decision with the penalty function, based on the analysis of train performance and its operation environment. Then a genetic algorithm is developed to solve this model and obtain the optimal recommended speed profiles. Thirdly, fuzzy controller is designed to achieve track recommended speed profiles. Finally, with the help of Matlab software, control effect is verified based on simulation. From the simulation results, it can be seen this strategy can meet the requirement of multi-objective, which are energy-saving, parking precisely, running punctually and comfort.
\end{abstract}

Keywords

automatic train operation, multi-objective, speed profile tracking, energy-efficiency train control

\section{Introduction}

When the automatic train operation (ATO) was just beginning to emerge, maximum speed strategy is one of the simplest trains running strategies and widely used. The maximum speed strategy will use the maximum acceleration to start until the speed reaches the speed limits of the track. The braking is also used the maximum deceleration to make the train stop. This strategy often makes the speed profile close to the speed limit, energy consumption is large and acceleration switching frequently.

Energy-efficient train control (EETC) is one of the research hotspots in railway train operation. EETC or eco-driving means drive a train with the least amount of energy (Scheepmaker et al., 2017). Even the energy-efficient is important, it's not the only one aim of the train operation. A good train operation strategy should be safe, punctually, comfort, parking precisely, etc.. Now lots of researchers try to find the best running operation sequence of automatic train operation system to reduce energy consumption. It's proved that proper strategy can make big decrease in energy saving (Domínguez et al., 2011).
The new Communication Based Train Control (CBTC) system can largely improve the communication band width, which can load more speed profiles (Carvajal-Carreño et al., 2014). Usually, the route is separated as several sections according the route characteristics, and several train control strategy is set, then algorithm is used to solve the optimal problem (Açıkbaş and Söylemez, 2008). There are many algorithm used to solve this problem, such as genetic algorithm, particle swarm optimization algorithm, Hybrid Evolutionary Algorithm, etc. (Domínguez et al., 2014; Miyatake and Ko, 2010; ShangGuan et al., 2015). As for speed tracking, fuzzy control is the most popular control method (Sicre et al., 2014; Yang et al., 2017).

This paper focuses on the multi-objective and uses the advantages of this two main study methods, which combines with intelligent optimization algorithm and fuzzy control. The multi-objective optimization method has been used to train operation control, but the different dimension of the problem has not been solved (Xun et al., 2008; Zhu et al., 2013). Based on the analysis of train performance and its operation environment, this paper unifies dimensions of 
different objectives by applying multi-objective decision with the penalty function. This method is of great significance to improve the operation efficiency and to reduce the operating costs of urban railway.

The structure of this paper is as follows:

- Section 2 analyzes the multi-objective model

- and Section 3 gets the strategy which generated by genetic algorithm.

- Section 4 designs the fuzzy control system, then use the speed profile generated in last section as the input to verify the control effect.

- Section 5 draws the conclusions.

\section{Multi-objective model}

\subsection{Mechanical analysis}

The train is considered as an entirety to analyze the force of the train. This paper defines the unit resultant force of the train as Eq. (1). $F_{t}$ is traction, $W$ is resistance (which includes basic resistance and additional resistance) and $B$ is braking force. The $P$ is the mass of the trailer and $G$ is the mass of the traction locomotive.

$f=\frac{F \times 1000}{\left(\sum P+\sum G\right) g}=\frac{\left(F_{t}+R+B\right) \times 1000}{\left(\sum P+\sum G\right) g}=f_{t}+r_{b}+r_{a}+b$

Calculating the actual train traction need find out the corresponding type of train traction characteristic curve, and then the value of the traction of different speed can be getting. There are three types train in China, which are Type A ( $3 \mathrm{~m}$ in width), Type B (2.8 $\mathrm{m}$ in width) and Type $\mathrm{C}$ ( $2.6 \mathrm{~m}$ in width). Type $\mathrm{A}$ is the most common urban railway train type in China, so the characteristics used in this research is accord with Type A Train. According to the Specification for Train Traction Computation (Ministry of Railways, 1999), the unit traction of the Type A train is as the following Eq. (2).

$f_{t}=\left\{\begin{array}{lc}\frac{(320-0.4779 v)}{\left(\sum p+\sum G\right) g} & 0 \leq v \leq 40 \mathrm{~km} / \mathrm{h} \\ \frac{7400}{v \cdot\left(\sum p+\sum G\right) g} & 40 \mathrm{~km} / \mathrm{h} \leq v \leq 90 \mathrm{~km} / \mathrm{h}\end{array}\right.$

The resistance $R$ is composed of basic resistance $R_{b}$ and additional resistance $R_{a}$, namely $R=R_{b}+R_{a}$. Referring the research of $\mathrm{Lu}$ (2016), the unit basic resistance is shown in Eq. (3), and the constants $A, B$ and $C$ is varies from the different train type. When trains run on the ramp, curve or tunnels, additional resistance can be calculated as Eq. (4) (Liu et al., 2008). The $r_{a}$ is the additional resistance, which contains ramp resistance $r_{r}$, curve resistance $r_{c}$ and tunnel resistance $r_{t} . I$ is the value of slope which is positive when uphill and negative when downhill, $R$ is curve radius of the curve rail track. $A$ is an empirical constant determined by experimental method and it varies from countries to countries, is usually 600 in China. $L_{s}$ is the length of the tunnel when the train runs in the tunnel.

$r_{a}=A+B v+C v^{2}=2.7551+0.14 v+0.00075 v^{2}$

$r_{b}=r_{r}+r_{c}+r_{t} \approx\left(I+\frac{A}{R}+0.00013 L_{s}\right)$

From the study of Ding (2011), the equation of unit braking force of type $A$ is as following Eq. (5). $K$ is braking force of each brake shoe of train.

$b=\frac{1000\left[0.372 \frac{17 v_{i+1}+100}{60 v_{i+1}+100}+0.0012\left(120-v_{i}\right)\right] \sum K}{\left(\sum P+\sum G\right) g}$

\subsection{Dynamics equations}

The dynamic equations are analyzed in this section, such as distance, speed and acceleration etc..

According to Newton's second law of motion, the acceleration of the train can be calculated as Eq. (6) (Zhu and $\mathrm{Xu}, 2011)$.

$a=\frac{F}{\left(\sum p+\sum G\right)}$

The rail track between two stations can be divided into several sections, and it is assumed that the train runs in a uniform acceleration in one section due to the fast speed of the train and the short distance of each section. From the definition of velocity and acceleration of classical mechanics, the speed and distance at section $i$ can be known as Eqs. (7), (8). $v_{i}$ is the velocity when train runs to $i$ distance. $t_{i}$ is the train running time of $i$ distance. $a_{i}$ is the acceleration of train running to $i$ distance. $s_{i}$ is the displacement of the train running to $i$ distance.

$v_{i}=v_{i-1}+a_{i}\left(t_{i}-t_{i-1}\right)$

$s_{i}=s_{i-1}+\frac{\left(v_{i}^{2}-v_{i-1}^{2}\right)}{2 a\left(t_{i}-t_{i-1}\right)}$

\subsection{Multi-objective model}

ATO control system is a complex nonlinear system, which has multiple input and output variables to realize multi-objective optimization. This paper proposes the 
multi-objective model in Eq. (9), which represents the optimal aim. $K_{e}, K_{a}, K_{p}$, and $K_{c}$ represent the various performance indicators of the train operation.

$$
\min f\left(v_{1}, v_{2}, \ldots, v_{n-1}, T^{\prime}, S^{\prime}\right)=\min \left(K_{e}, K_{a}, K_{p}, K_{c}\right)
$$

$K_{e}$ is the value of the energy consumption, and from the power definition of classical mechanics, Eq. (10) is obtained. If the smaller the $K_{e}$ is, the less energy will be used. $F_{i}$ is a resultant force on the $i^{\text {th }}$ section. $S^{\prime}$ is the actual distance that the train run.

$$
K_{e}=\sum_{i=1}^{n}\left|F_{i} \cdot \frac{S^{\prime}}{n}\right|=\sum_{i=1}^{n}\left|\left(f_{t i}-r_{i}-b_{i}\right)\left(\sum P+\sum G\right) \cdot \frac{S^{\prime}}{n}\right|
$$

This paper proposes Eq. (11) to calculate the $K_{a}$, which means the stop accuracy of the train. The smaller the value of $K_{a}$ indicates more accurate. $S$ is the stand distance of the train that should be run. This paper chooses the difference value between $S^{\prime}$ and $S$ to represent the accuracy of train. Penalty coefficient $\sigma$ is making the calculation more precisely. The $\sigma$ means the unit additional energy when the train parks on the standard parking position. The $\sigma_{0}$ is the deviation of train position that obtained with the maximum traction force.

$$
K_{a}=(1+\sigma)^{\frac{\left|S^{\prime}-S\right|}{\sigma_{0}}}
$$

$K_{p}$ represents the index of train punctuality. Referred to the research of Chang and Sim (1997), Eq. (12) is established to express $K_{p}$. $T$ represents the time that the train should finish the running, which is get from running schedule. The actual time, that the train is running the whole route, is $T^{\prime} . \tau_{0}$ represents the time limit that passengers can acceptable the train arrive early or late. $\tau$ is also set to be a time penalty coefficient, which represents energy consumption value which can make train finish running at time $T$.

$K_{p}=(1+\tau)^{\frac{\left|T^{\prime}-T\right|}{\tau_{0}}}$

The index of passengers comfort is $K_{c}$, and it's expression is proposed in Eq. (13). $C^{\prime}$ represents the uncomfortable level, which is measured by the jerk and calculated by $d a / d t$ (Ke et al., 2011). The smaller $C^{\prime}$ means more comfortable, that passengers feel. The maximum jerk that passengers can bear is $C . \alpha$ is a penalty function of train energy consumed to make train running meet the comfortable level.

$$
K_{c}= \begin{cases}(1+\alpha)^{\left|\frac{C^{\prime}}{C}\right|} & C^{\prime}>C \quad C^{\prime}=\sum_{i=1}^{n}\left|\frac{a_{i}-a_{i-1}}{t_{i}-t_{i-1}}\right| \\ 1 & C^{\prime} \leq C\end{cases}
$$

\section{Strategy generation}

\subsection{Algorithm and parameter}

Speed profile is the speed that the train should be at time $t$, different speed profile will lead to different optimization result. Appropriate algorithm need to be chosen to generate the recommended speed profile. The train operation is a complex, nonlinear multi-objective optimization problem. It's hard to get exact solution, genetic algorithm is used to get the speed profile. Genetic algorithm is an optimization algorithm based on biological natural selection and natural genetic mechanism, which is widely used in combinatorial optimization, machine learning, adaptive control and other fields. Good convergence, higher precision, less computation time and higher robustness are the advantages that genetic algorithm own (Xia et al., 2006).

Before the genetic algorithm applied, it is necessary to explicit the environment of train operation and the train attributes as a basic experimental characteristics. This study of the automatic train running strategy is based on the vehicle of $6 \mathrm{~A}$ formation. The property parameters of the train are shown in the Table 1. The environment parameters between two stations in Beijing Railway is acquired and shown in the Table 2.

\subsection{Speed profile generation}

Matlab software and genetic algorithm are used to find the optimal speed profile in this paper. The route is divided into $n$ sections $(n=100)$, after the $96^{\text {th }}$ calculation, the optimum solution can be get. So the 100 is set to be the stop of

\begin{tabular}{|c|c|}
\hline Parameter name & Size parameters \\
\hline Train Formation & $\begin{array}{l}6 A \text { formation, } 4 \text { motor cars and } 2 \text { trailers } \\
\text { Organization form: Tc-Dc-Dc-Dc-Dc-Tc } \\
\text { Tc refers to trailer having the driver cab } \\
\text { Dc refers to train without the driver cab }\end{array}$ \\
\hline Train length & $22.8 \mathrm{~m}$ \\
\hline Body width & $3 \mathrm{~m}$ \\
\hline $\begin{array}{l}\text { The passenger } \\
\text { capacity of the } \\
\text { train }\end{array}$ & $\begin{array}{l}\text { Seating capacity is } 56 \text { people per cab } \\
\text { Standard capacity is } 310 \text { people per cab } \\
\text { Over capacity is } 430 \text { people per cab }\end{array}$ \\
\hline Train weight & $\begin{array}{c}\text { Weight under no-load: } 220 \mathrm{t} \\
\text { Weight under standard load: } 332 \mathrm{t} \\
\text { Weight under over load: } 375 \mathrm{t} \\
\text { (Weight is calculated on } 60 \mathrm{~kg} \text { per passenger) }\end{array}$ \\
\hline Top speed & $80 \mathrm{Km} / \mathrm{h}$ \\
\hline $\begin{array}{l}\text { The total pressure } \\
\text { of brake shoe }\end{array}$ & $\sum K=810 \mathrm{KN}$ \\
\hline
\end{tabular}
the operation in the speed profile generate. Then, the value of $v_{1}, v_{2}, \ldots, v_{99}, v_{100}, T^{\prime}, S^{\prime}$, etc. can be get from the optimum

Table 1 The property parameters of the train 
Table 2 The environment parameters between the two stations

\begin{tabular}{lc}
\hline Basic attributes of line & The values \\
\hline Total route length $S$ & $1000 \mathrm{~m}$ \\
Orbit curve radius $R$ & $1200 \mathrm{~m}$ \\
The tunnel length $L_{s}$ & $1000 \mathrm{~m}$ \\
The slope $i$ between $0-500 \mathrm{~m}$ & $-5 \%$ \\
The slope $i$ between $500-1000 \mathrm{~m}$ & $10 \%$.
\end{tabular}

solution. In the recommended speed profile of the multi-objective strategy, the running time is 120.3 seconds and the energy consumption is $5.63 \times 10^{7}$ joule. Potting each speed value $v_{0}, v_{1}, v_{2}, \ldots, v_{99}, v_{100}$ at corresponding section point, Fig. 1 can show the $v$-s relationship.

Combing figures and numeric results of multi-objective strategy, it can be seen that within the time, the energy consumption and stop accuracy meet the requirement, and the comfortable level of passengers is smooth. Synthesize the relevant data, the speed profile that generate by multi-objective strategy performs good. The results above is generated based on the specific train and route environment in Beijing, but the way generate the multi-objective recommended speed profile is suitable for other train type and environment. The speed profile generated in this section would be the input of ATO controller. Under the circumstance that the controller can make train operate according to the speed profile, multi-objective automatic train operation can be realized.

\section{Speed profile tracking}

\subsection{Simulation system design}

To realize the multi-objective control strategy is generating train ideal speed profile of ATO and controlling the train on the accurate tracking process. Simulink environment of

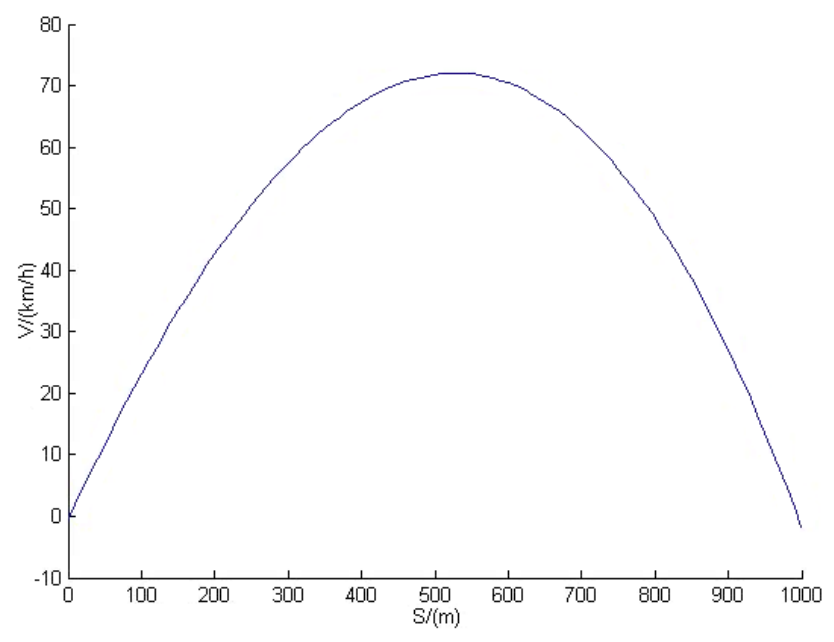

Fig. 1 The speed profile under multi-objective strategy
Matlab is applied to build simulation system, Fig. 2 shows the simulation system framework. The simulation system of multi-objective control strategy consists of ideal trajectory module of train, fuzzy controller module, predictive controller module and the module of the controlled object. Train ideal trajectory module inputs the ideal speed curve to the system as the tracking targets of ATO control system. Fuzzy controller outputs control commands to control train operation according to the variation of the input state. Predictive controller predicts the next time actual speed of the train based on the current operation speed and the change of ideal speed curve, which regards the error rate between predictive speed and ideal speed and make them to be the input of the fuzzy controller of the next moment. In addition, predictive controller makes the change of the external environment real-time feedback to the system to achieve the dynamic optimization.

\subsection{Fuzzy control design}

Fuzzy logic controller is the most important part of the fuzzy control system. The input and output of the fuzzy control system should be clarified. Forecast error $e$ and forecast error change rate $e^{\prime}=d e / d t$ are set to be the input of the fuzzy control. The output of the fuzzy system is the resultant force $u$.

Each fuzzy language is corresponding to a fuzzy set. Fuzzy segment is to confirm the number of fuzzy language name, which decided the accuracy of fuzzy control. In this paper, NB (Negative Big), NM (Negative Medium), NS (Negative Small), ZR (Zero), PS (Positive Small), PM (Positive Medium), PB Positive Big) is set to represent the space of input and output of the fuzzy control.

The precise value should be fuzzy to meet the requirement of fuzzy control. According to the research of Li and Yang (2013), Eq. (14) can be obtained to make the conversion. The fields of fuzzy parameter $e$ is $[-10,+10]$, the fields of $e^{\prime}$ is $[-6,+6]$ and $u$ is $[-10,+10]$.

$y=\frac{2 n\left(x-\frac{a-b}{2}\right)}{b-a}$

The triangular-shaped function is used to describe the membership function of fuzzy input and output. When the triangle is narrow, the control will be more sensitive, and wide triangle means the stable control. The shape of the triangle usually is decided by the input error. In order to make control more efficient, the middle triangle of $e$ is the narrowest, and gradually be wide to the sides, shown as Fig. 3. The membership function of $e^{\prime}$ and $u$ is Fig. 4 and Fig. 5. 


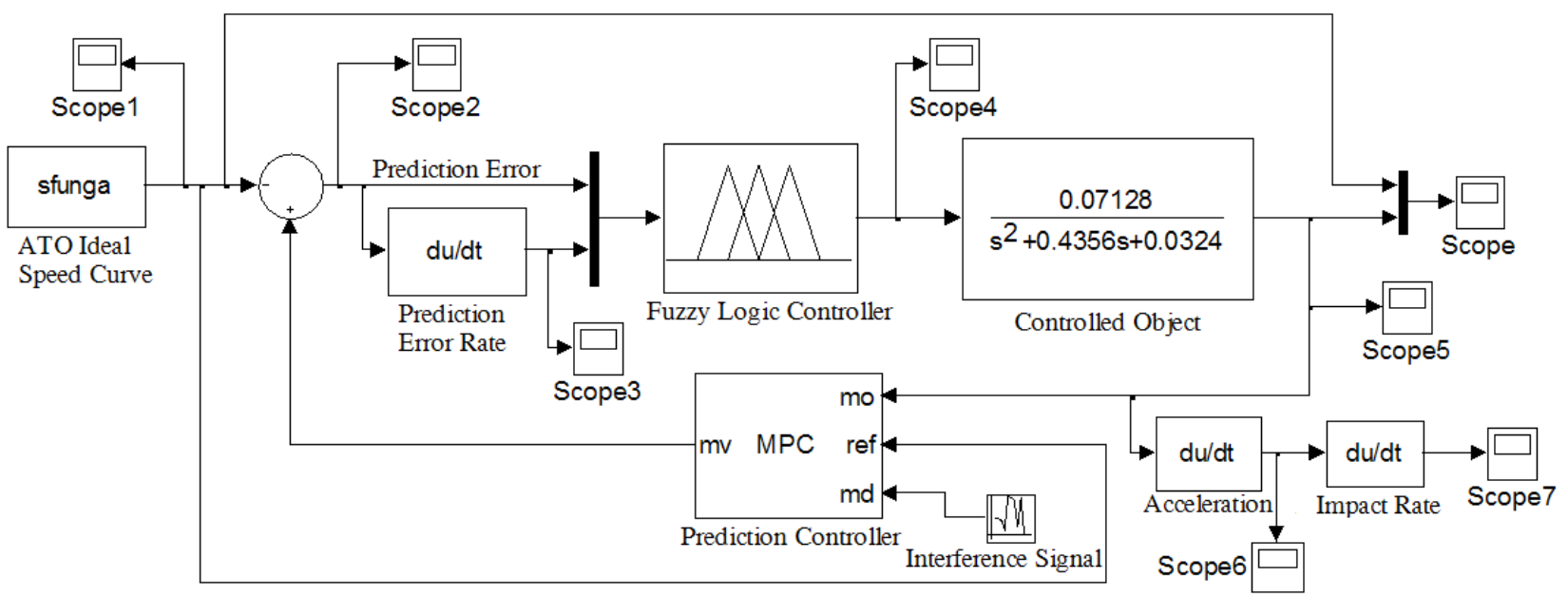

Fig. 2 Simulation system of multi-objective control strategy

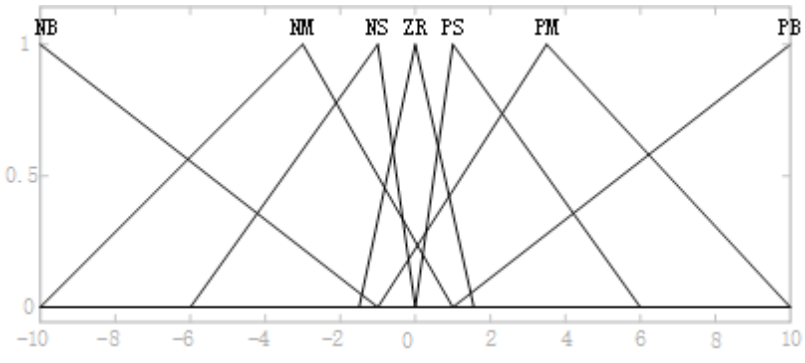

Fig. 3 Membership function of $e$

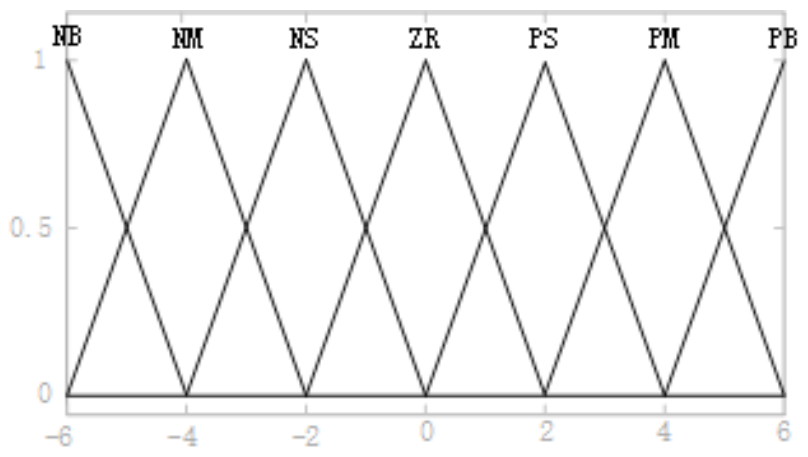

Fig. 4 Membership function of $e^{\prime}$

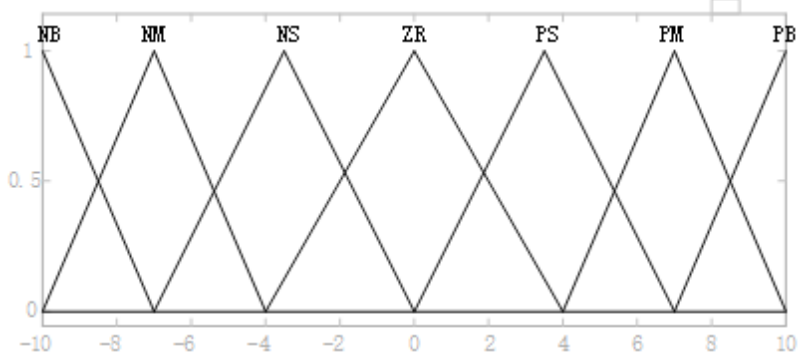

Fig. 5 Membership function of $u$
Appropriate fuzzy control rule is a critical part to realize fuzzy control. The fuzzy control rule is imitating the operation of the train driver, which is a knowledge set get by experiment. Use language to conclude the manual manipulation rule is actually to establish the fuzzy control rule. Generally speaking, conditional statements can describe the manual manipulation rule, such as if $\mathrm{A}$ and $\mathrm{B}$, then C. It should be noticed when chose the variation range of control variables, if the input error is big, output variable should cancel the errors. If the input error is small, output variable should prevent overshoot. Table 3 is the fuzzy control rule used in this paper.

\subsection{Result analysis}

The train characteristics and operation environment of the simulation is shown in the Table 1 and Table 2. The simulation is running with interference, then the energy saving, punctuality, accuracy and comfort are analyzed based on the simulation results, which aims to verify whether each performance index meets the requirements of automatic train operation. ATO simulation curve, the speed tracking error and jerk with interference are shown in Fig. 6, Fig. 7 and Fig. 8 respectively. And Table 4 shows the simulation results.

As it can see from the simulation results under the circumstance with interference, the maximum speed of automatic train operation is controlled under the $80 \mathrm{~km} / \mathrm{h}$ and the deviation between actual operating speed and ideal speed is not more than $2 \mathrm{~m} / \mathrm{s}$. The actual energy consumption ranges from $6.643 \times 10^{7} \mathrm{~J}$ to $6.664 \times 10^{7} \mathrm{~J}$ that is smaller than without applying ATO multi-objective control strategy, which is $7.924 \times 10^{7} \mathrm{~J}$. Running time is controlled 
Table 3 Fuzzy control rule

\begin{tabular}{lccccccc}
\hline$e e^{\prime}$ & NB & NM & NS & ZR & PS & PM & PB \\
\hline NB & PB & PB & PB & PB & PM & PS & ZR \\
NM & PB & PB & PM & PM & PS & ZR & ZR \\
NS & PB & PM & PM & PS & ZR & ZR & NS \\
NR & PM & PS & PS & ZR & NS & NS & NM \\
PS & PS & ZR & ZR & NS & NM & NM & NB \\
PM & ZR & ZR & NS & NM & NM & NB & NB \\
PB & ZR & NS & NM & NB & NB & NB & NB \\
\hline
\end{tabular}

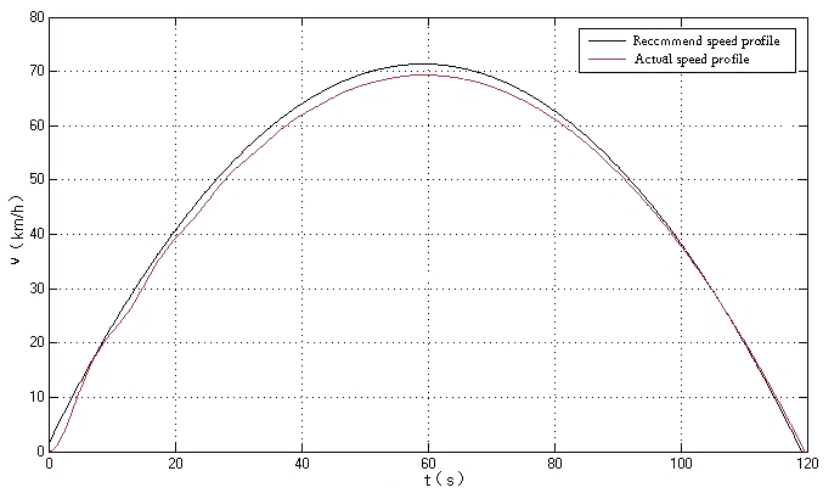

Fig. 6 ATO simulation speed profile

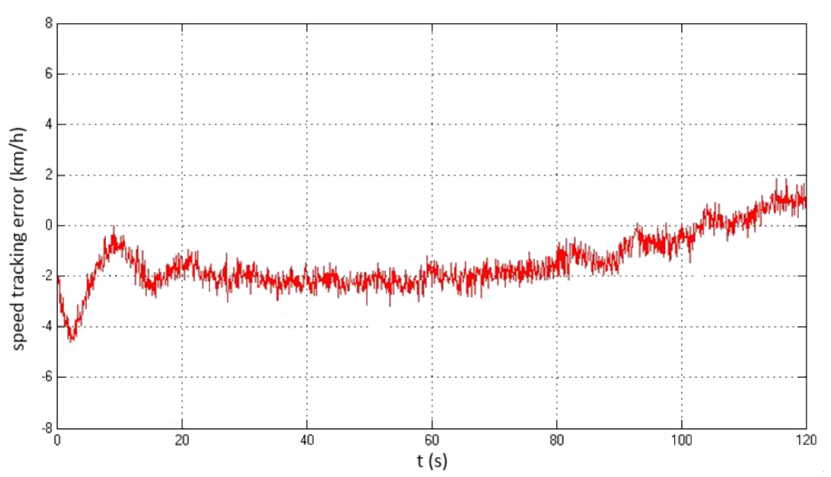

Fig. 7 ATO speed tracking error plot

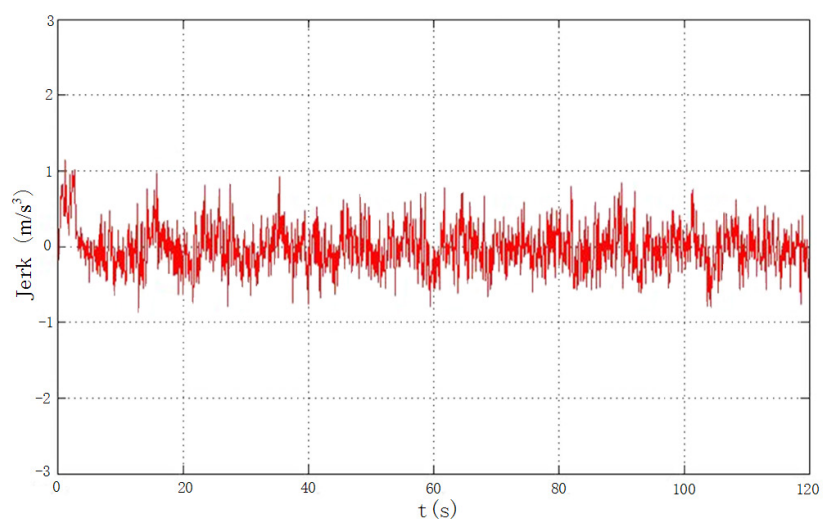

Fig. 8 ATO jerk plot
Table 4 Simulation results

\begin{tabular}{lcccc}
\hline Times & $\begin{array}{c}\text { Energy } \\
\text { consumption } \\
\mathrm{J}\end{array}$ & $\begin{array}{c}\text { Running } \\
\text { time } \\
\mathrm{s}\end{array}$ & $\begin{array}{c}\text { Running } \\
\text { distance } \\
\mathrm{m}\end{array}$ & $\begin{array}{c}\text { Maximum } \\
\text { absolute value } \\
\text { of jerk } \\
\mathrm{m} / \mathrm{s}^{3}\end{array}$ \\
\hline 1 & $6.643 \times 10^{7}$ & 124.82 & 999.95 & 1.33 \\
2 & $6.763 \times 10^{7}$ & 123.99 & 1000.01 & 1.41 \\
3 & $6.622 \times 10^{7}$ & 117.44 & 1000.07 & 1.42 \\
4 & $6.589 \times 10^{7}$ & 122.84 & 999.99 & 1.41 \\
5 & $6.684 \times 10^{7}$ & 123.99 & 999.80 & 1.46 \\
6 & $6.593 \times 10^{7}$ & 118.28 & 1000.20 & 1.39 \\
7 & $6.545 \times 10^{7}$ & 120.98 & 1000.01 & 1.20 \\
8 & $6.627 \times 10^{7}$ & 116.29 & 999.97 & 1.27 \\
9 & $6.745 \times 10^{7}$ & 120.96 & 999.93 & 1.40 \\
10 & $6.664 \times 10^{7}$ & 123.86 & 1000.09 & 1.36 \\
\hline
\end{tabular}

within the range $115 \mathrm{~s}$ and $125 \mathrm{~s}$ and the error limit is $\pm 5 \mathrm{~s}$ compared with the ideal operation time $120 \mathrm{~s}$. Actual running distance between the train stations are within the specified interval 999.75 and 1000.25 . The actual acceleration of the train has larger changes only in the start-up phase and it changes small in the interval running that the jerk all the way is within the range $-1.5 \mathrm{~m} / \mathrm{s}^{3}$ and $1.5 \mathrm{~m} / \mathrm{s}^{3}$. The above analysis shows that automatic train operation have achieved the multiple requirements of safety, energy saving, punctuality, accuracy and comfort. In addition, the train will fluctuate after the interference, but soon return to track the ideal speed curve that embodies the good anti-interference and stability of the fuzzy predictive controller of the ATO multi-objective control strategy.

\section{Conclusion}

This study focuses on the problem of ATO strategy optimization. To overcome the contradiction between objectives and unify theirs measurement unit, penalty function is used to establish the multi-objective model. Then the recommended speed profile is obtained by genetic algorithm. To confirm the effectiveness of the method used in this paper, a simulation is implemented by the Simulink of Matlab software. The simulation result shows that all the performance indexes meet the requirement of train operation according to the actual operation environment. Furthermore, the system is robust under the circumstances of some interferes.

The main result of this paper is our multi-objective model of ATO is well-performed in the verification by simulation. From Table 4, we can know that:

1. The average energy consumption is $6.6475 \times 10^{7}$ joule, which decrease the energy consumption about $16 \%$ compare with before. 
2. Running time meet the requirement of $\pm 5 \mathrm{~s}$.

3. The train meets the requirement of the stop accuracy $\pm 0.25 \mathrm{~m}$.

4. The absolute value of jerk meet the requirement of less than $1.5 \mathrm{~m} / \mathrm{s}^{3}$.

It can be seen that the energy saving, stop accuracy, punctuality and comfortable all qualified. The effective speed profile means the multi-objective model is effective.

The method used in this paper does not limited by the specific train type and route, other situations can also applied by change the parameters.

In this study, the running train is abstracted as an mathematic model, which simplifies some complex situations.

\section{References}

Açıkbaş, S., Söylemez, M. T. (2008) "Coasting point optimisation for mass rail transit lines using artificial neural networks and genetic algorithms", IET Electric Power Applications, 2(3), pp. 172-182. https://doi.org/10.1049/iet-epa:20070381

Carvajal-Carreño, W., Cucala, A. P., Fernández-Cardador, A. (2014) "Optimal design of energy-efficient ATO CBTC driving for metro lines based on NSGA-II with fuzzy parameters", Engineering Applications of Artificial Intelligence, 36, pp. 164-177. https://doi.org/10.1016/j.engappai.2014.07.019

Chang, C. S., Sim, S. S. (1997) "Optimising train movements through coast control using genetic algorithms", IEE Proceedings - Electric Power Applications, 144(1), pp. 65-73. https://doi.org/10.1049/ip-epa:19970797

Ding, Y. (2011) "列车运行计算与设计", (The train operation calculation and design) 1st ed., Beijing Jiaotong University Press, Beijing, China. (in Chinese)

Domínguez, M., Fernández, A., Cucala, A. P., Lukaszewicz, P. (2011) "Optimal design of metro automatic train operation speed profiles for reducing energy consumption", Proceedings of the Institution of Mechanical Engineers, Part F: Journal of Rail \& Rapid Transit, 225(5), pp. 463-474. https://doi.org/10.1177/09544097JRRT420

Domínguez, M., Fernández-Cardador, A., Cucala, A. P., Gonsalves, T., Fernández, A. (2014) "Multi objective particle swarm optimization algorithm for the design of efficient ATO speed profiles in metro lines", Engineering Applications of Artificial Intelligence, 29, pp. 43-53.

https://doi.org/10.1016/j.engappai.2013.12.015

Ke, B.-R., Lin, C.-L., Lai, C.-W. (2011) "Optimization of trainspeed trajectory and control for mass rapid transit systems", Control Engineering Practice, 19(7), pp. 675-687. https://doi.org/10.1016/j.conengprac.2011.03.003

Li， G.，Yang， L. (2013) "神经・模糊・预测控制及其MATLAB实现" (Neural, fuzzy, predictive control and their MATLAB implementation), 3rd ed., Publishing House of Electronics Industry, Beijing, China. (in Chinese)
Future study will consider more details to make the control more precisely. Applying this method to the actual environment would be the best way to measure the performance of multi-objective train operation strategy if the condition allows. Other factor, such as weather, load, regenerative energy etc. would be studied to control the train more accurately. Besides, we will study other methods of problem solving, especially particle swarm and NSGA-II.

\section{Acknowledgement}

This work was partially supported by the Fundamental Research Funds for the Central Universities under grant number 2017YJS167.

Liu, X., Zhang, Y., Tang, Z. (2008) "城市轨道交通智能控制系统" (Urban rail transit intelligent control system), 1st ed., China Railway Press, Beijing, China. (in Chinese)

Lu, J. (2016) "城市规定交通列车牵引与操纵" (Train traction and operation of urban rail transit", 2nd ed., Southwest Jiaotong University Press, Chengdu, China. (in Chinese)

Ministry of Railways (1999) "TB/T 1407-1998 Specification for Train Traction Computation", Ministry of Railways, China.

Miyatake, M., Ko, H. (2010) "Optimization of Train Speed Profile for Minimum Energy Consumption", IEEJ Transactions on Electrical and Electronic Engineering, Special Issue on Energy Saving Technologies on Electric Railways in Japan, 5(3), pp. 263-269. https://doi.org/10.1002/tee.20528

Scheepmaker, G. M., Goverde, R. M. P., Kroon, L. G. (2017) "Review of energy-efficient train control and timetabling", European Journal of Operational Research, 257(2), pp. 355-376. https://doi.org/10.1016/j.ejor.2016.09.044

ShangGuan, W., Yan, X.-H., Cai, B.-G., Wang, J. (2015) "Multiobjective Optimization for Train Speed Trajectory in CTCS High-Speed Railway With Hybrid Evolutionary Algorithm", IEEE Transactions on Intelligent Transportation Systems, 16(4), pp. 2215-2225. https://doi.org/10.1109/TITS.2015.2402160

Sicre, C., Cucala, A. P., Fernández-Cardador, A. (2014) "Real time regulation of efficient driving of high speed trains based on a genetic algorithm and a fuzzy model of manual driving", Engineering Applications of Artificial Intelligence, 29, pp. 79-92. https://doi.org/10.1016/j.engappai.2013.07.015

Xia, K., Zhao, M., Yang, L. (2006) "A Self-Adaptive Genetic Algorithm for Multi-Objective Reactive Power Optimization", Power System Technology, 30(13), pp. 55-60.

Xun, J., Ning, B., Li, K. P. (2008) "Multi-objective Optimization Method For The ATO System Using Cellular Automata", In: Allan, J., Arias, E., Brebbia, C. A., Goodman, C. J., Rumsey, A. F., Sciutto, G., Tomii, N. (eds.) Computers in Railways XI: Computer System Design and Operation in the Railway and other Transit Systems, Vol. 103, 1st ed., WIT Press, Southampton, UK, pp. 173-182. https://doi.org/10.2495/CR080181 
64 Zhu et al.

Period. Polytech. Transp. Eng., 48(1), pp. 57-64, 2020

Yang, J., Jia, L., Fu, Y., Lu, S. (2017) "Speed Tracking Based EnergyEfficient Freight Train Control Through Multi-Algorithms Combination", IEEE Intelligent Transportation Systems Magazine, 9(2), pp. 76-90.

https://doi.org/10.1109/MITS.2017.2666580

Zhu, X., Xu, Z. (2011) "Dynamic Simulation of Urban Rail Transit Train Based on Single-Particle Model", Journal of the China Railway Society, 33(6), pp. 14-19.

https://doi.org/10.3969/j.issn.1001-8360.2011.06.003

Zhu, X., Zhang, R., Dai, W., Zhang, Z., Li, J. (2013) "Performance and Safety Assessment of ATO Systems in Urban Rail Transit Systems in China Journal of Transportation Engineering, 139(7), pp. 728-737. https://doi.org/10.1061/(ASCE)TE.1943-5436.0000550 